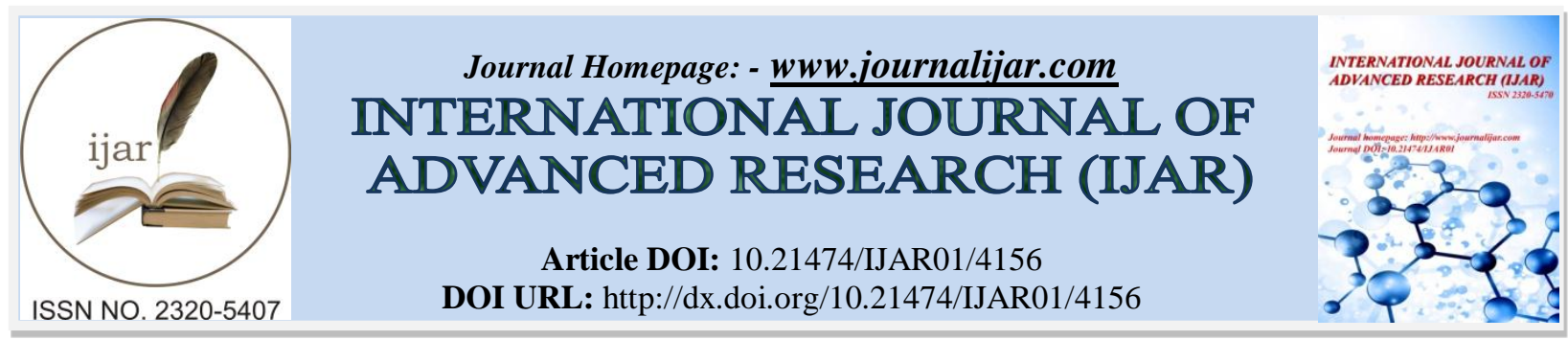

RESEARCH ARTICLE

\title{
COMPARATIVE EFFICACY OF DEXAMETHASONE WITH LOCAL ANESTHETIC SOLUTION AND 2\% LIGNOCAINE WITH 1:200000 ADRENALINE IN REDUCING POST-OPERATIVE DISCOMFORT IN PATIENTS OF SURGICAL REMOVAL OF IMPACTED MANDIBULAR THIRD MOLAR: A PROSPECTIVE RANDOMIZED STUDY.
}

\author{
Dr. Udit Prakash ${ }^{1}$, Prof. Dr. Nitin Jaggi ${ }^{2}$, Prof. Dr. Ashish Singh $^{3}$, Dr. Nikhil Purohit ${ }^{4}$ and Dr. Moin Iftikhar \\ Shapoo ${ }^{1}$. \\ 1-PG Student, 2-HOD, 3-Professor, 4-Reader - Department Of Oral \& Maxillofacial Surgery, Maharana Pratap \\ College Of Dentistry \& Research Center, Gwalior.
}

\section{Manuscript Info \\ Manuscript History \\ Received: 10 March 2017 \\ Final Accepted: 13 April 2017 \\ Published: May 2017}

Key words:-

Lignocaine. Local anesthesia Dexamethasone. Inferior alveolar nerve bock . Pterygomandibular nerve block . Nerve block . Buffered local anesthetic.

\begin{abstract}
Introduction: A prospective, randomized study was conducted to assess the efficacy of solution A (mixture of $1.8 \mathrm{ml} 2 \%$ lignocaine with 1:200000 adrenaline and $1 \mathrm{ml}$ of dexamethasone) on the post-operative sequelae and compare it with $2 \%$ lignocaine with 1:200000 adrenaline in patients with need of surgical extraction of bilateral impacted mandibular teeth.

Materials and methods: A group of 40 patients with need of surgical extraction of bilateral impacted mandibular teeth were chosen for the study with a total of 80 interventions, 40 with twin mix(study group A) and 40 with 2\%lignocaine with 1:200000 adrenaline(group B)After injection of the anesthetic solution, the time to anesthetic effect, duration of anesthesia, and the need to re-anesthetize the surgical site were recorded. Overall pain intensity and $\mathrm{pH}$ of the test anesthetic solutions was also determined. Post operative pain, swelling and mouth opening was measured at $1^{\text {st }}, 3^{\text {rd }}$ and $7^{\text {th }}$ day post-operatively. The results obtained were compared using student-t test.

Results: On comparative evaluation between control group B and study group A, patients in the control group had more severe intra-operative and post-operative sequelae.

Discussion: The post -operative sequelae namely swelling, pain and reduced mouth opening was less in the side given $4 \mathrm{mg}$ dexamethasone along with the local anesthetic solution than local anesthesia alone. Also there was a significant improvement in the time of onset and the time duration of local anesthesia.
\end{abstract}

Copy Right, IJAR, 2017,. All rights reserved.

\section{Introduction:-}

Jaw movements are required for vital day to day activities like speech and mastication. Any abnormality can seriously hamper these functions of an individual. Surgical removal of mandibular impacted third molar can cause trauma to the surrounding tissues and can limit these vital activities for a significant period of time. The usual post-

Corresponding Author:-Dr. Udit Prakash

Address:-Dept. Of Oral \& Maxillofacial Surgery, Maharana Pratap College Of Dentistry \& Research 
operative sequelae are pain, swelling, and trismus. Sensory nerve damage, dry socket, hemorrhage and infection can also occur ${ }^{1}$.

Most surgeons utilize corticosteroids based on the recognized efficacy to control surgery outcomes and to yield a comfortable post-surgery period ${ }^{2}$. Corticosteroids, like dexamethasone, methylprednisolone and betamethasone are potent and widely used inhibitors of inflammation because of their suppressive impact on the synthesis and release of inflammatory tissue mediators. A significant reduction of oedema and trismus following steroid application after mandibular third molar removals has been reported as well as a decrease in post-interventional pain ${ }^{3}$.

The purpose of this study is to investigate the efficacy of dexamethasone in reducing the post-operative sequelae, if used along with the local anesthetic solution.

\section{Materials and methods:-}

A prospective randomized double-blind study was conducted on 40 subjects planned for elective surgical removal of bilateral mandibular third molars. All patients in which bilateral mandibular third molar have to be removed and with an age range of 18-45yrs were included in the study.

The exclusion criteria were the existence of swelling and pain at the time of surgery, systemic disorders, any allergic disorders or any history of complications associated with extraction of teeth.

2 groups were made of 20 interventions each. In one patient, both interventions were given on opposite sites with a minimum gap of 3 weeks between both interventions. The interventions were divided into 2 groups. In Group A, solution A was used for local anesthesia and in group B, solution B is used (2\% lignocaine with 1:200,000 adrenaline) for local anesthesia. Solution A was prepared by mixing $1.8 \mathrm{ml} 2 \%$ lignocaine with 1:200,000 epinephrine and $1 \mathrm{ml}$ dexamethasone inj. $(4 \mathrm{mg}) .1 .8 \mathrm{ml}$ lignocaine is used so that the amount of solution injected will be same in both the groups.

Following recordings were taken:

1) The time to anesthetic effect.

2) The duration of anesthesia.

3) A 10-point visual analog scale (VAS) was used to subjectively assess the overall pain intensity while injecting the drug and in the postoperative period.

4) $\mathrm{pH}$ of the test anesthetic solutions

5) Post-operative mouth opening and facial swelling was also recorded at $1^{\text {st }}, 3^{\text {rd }}$ and $7^{\text {th }}$ post-operative day.

\section{Results:-}

Prospective randomized double-blind clinical trial on 40 subjects out of which 28 were male patients and 12 females with a mean age of 27 years, with an age range 18-45 years planned for elective surgical removal of bilateral mandibular third molars. All the 80 nerve blocks (40 in each study group) using the 2.8-ml study solution were successful, not requiring re-anesthesia. The $\mathrm{pH}$ of the study solutions were tested with a $\mathrm{pH}$ meter which indicates that solution A is more basic than solution B. Recovery from the local anesthetic was complete, without any residual deficit in all the patients in both the study groups.

The mean time recorded for the oral surgical procedure was 48.9 \pm 4.20 min for study group A and 44.7 \pm 5.0 min for control group B, showing no statistical difference $(\mathrm{p}>0.05)$. Mean VAS value for the pain/sting on local anesthetic injection/block was less in study group A. Time of onset of the local anesthetic was significantly less for the study group A, $1.40 \pm 0.36 \mathrm{~min}$, when compared with patients in control group B which was $2 \pm 0.52$ min $($ Table $1, \mathrm{p}<0.05)$. The duration of soft tissue anesthesia was clinically longer for all the patients in the study group A, though not statistically significant (Table 1). In both the groups A and B, facial swelling was seen maximum on the first postoperative day followed by reduction in the swelling on $3^{\text {rd }}$ and $7^{\text {th }}$ day. On comparative evaluation between study group A and control group B, patients in the control group had more severe swelling and more reduction in mouth opening in the postoperative period (Table 2 and Fig.1). Mouth opening was found better post-operatively in study group A on $1^{\text {st }}, 3^{\text {rd }}$ and $7^{\text {th }}$ day (Table 3 and Fig. 2 ).

Post-operative pain (VAS score) was found to be less in study group A then our group B (Table 4 and Fig. 3) 


\begin{tabular}{|l|l|l|}
\hline & Group A & Group B \\
\hline Pain while injecting drug(VAS) & $5+-1.15$ & $6+-1$ \\
\hline Time of onset of anesthetic effect(minutes) & $1: 40+-0.36$ & $2+-0.52$ \\
\hline Time duration of anesthesia(in hours) & $3: 45+-0.3$ & $3: 20+-0.46$ \\
\hline
\end{tabular}

Table 1:- Intra-operative parameters

\begin{tabular}{|l|l|l|}
\hline Facial swelling & Group A & Group B \\
\hline${\text { Day } 1^{\text {st }}}_{\text {rd }}$ & $12.4+-0.62$ & $12.6+-0.63$ \\
\hline Day 3 & $12.3+-0.64$ & $12.5+-0.64$ \\
\hline Day $^{\text {th }}$ & $12.1+-0.63$ & $12.2+-0.65$ \\
\hline
\end{tabular}

Table 2:- Facial swelling

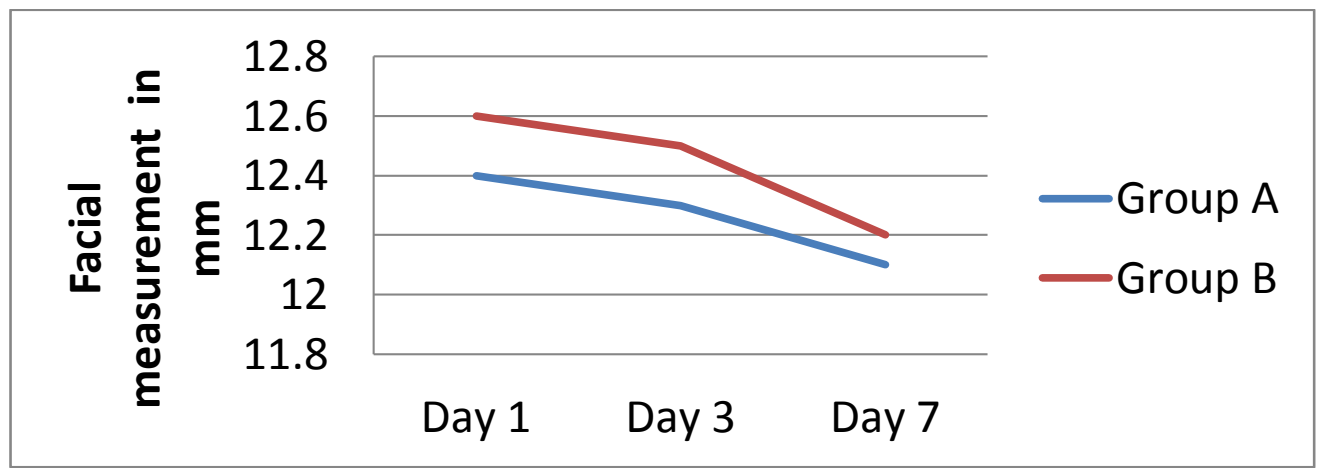

Figure 1:- Facial swelling

\begin{tabular}{|l|l|l|}
\hline Mouth opening & Group A & Group B \\
\hline Day 1 $^{\text {st }}$ rd $^{\text {Day 3 }}$ & $40+-10.3$ & $39.2+-1.14$ \\
\hline Day 7 $^{\text {th }}$ & $43.5+-9$ & $41.7+-1.13$ \\
\hline
\end{tabular}

Table 3:- Mouth opening

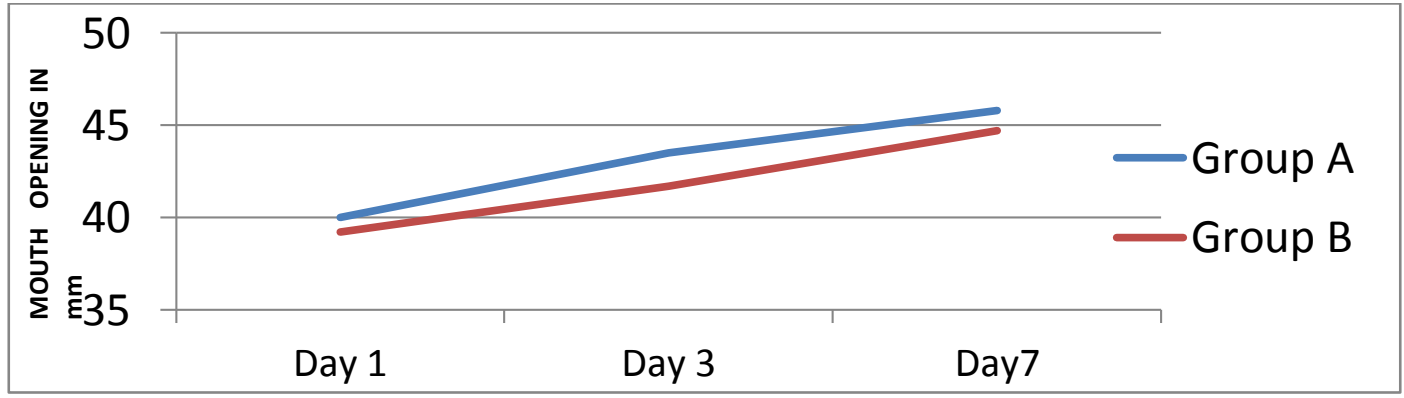

Figure 2:- Mouth opening

\begin{tabular}{|l|l|l|}
\hline Post-operative VAS & Group A & Group B \\
\hline Day 1 $^{\text {st }}$ rd $^{\text {Day 3 }}$ & $4+-1.34$ & $4.8+-1.32$ \\
\hline Day $^{\text {th }}$ & $2.1+-1.78$ & $2.7 \pm 1.28$ \\
\hline
\end{tabular}

Table 4:- Post-operative pain 


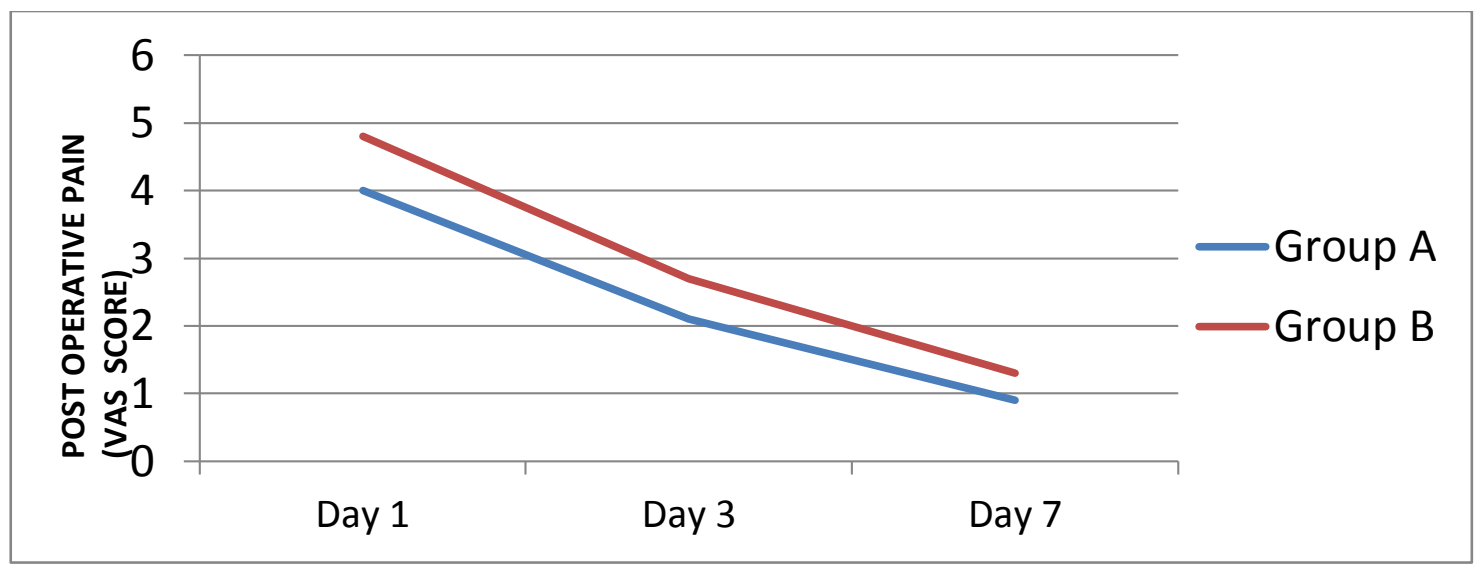

Figure 3:- Post-operative pain

\section{Discussion:-}

The surgical removal of impacted third molars produces significant post-operative sequelae and many researchers have tried different treatment protocols to reduce these adverse symptoms and to increase the post-operative quality of life of patients.

Most surgeons utilize corticosteroids based on the recognized efficacy to control surgical outcomes and to yield a comfortable post-surgery period.

Glucocorticoids are suppressor agents of multiple signaling pathways involved in the inflammatory response leading to decreased levels of inflammatory mediators at the site ${ }^{1}$. They represent the most efficacious anti-inflammatory agents and to this purpose can be used in several different conditions. Often used in oral surgery are long acting corticosteroid compounds. Among these, the most frequently used is dexamethasone that is about 25-30 times more potent than cortisol. It is largely used pre- or post-surgery due to its high efficacy and long half-life ${ }^{2}$.

Alkalinization of local anesthetic agents may shorten the onset time and lengthen their duration of action, decreases pain on injection and also improves overall the patients postoperative comfort and quality of life ${ }^{4}$. Local anaesthetics exist in equilibrium between the basic uncharged (non-ionized) form, which is lipid soluble, and the charged (ionized) cationic form, which is water soluble. Lipid soluble, non-ionized form of the local anaestheticpenetrates the neural sheath and membrane. The ionized form of the local anaesthetic binds with the sodium channel and prevents propagating of impulses. Altering the $\mathrm{pH}$ to a more basic solution will increase the amount of non-ionized form compared to ionized form which will speed onset. ${ }^{5,6}$. Steroid induced shorter onset and prolonged duration, apart from change in $\mathrm{pH}$, which may also be due to the property of vasoconstriction dexamethasone has, or by increase in the activity of the inhibitory potassium channels on nociceptive $\mathrm{C}$-fibres (via glucocorticoid receptors), thus decreasing their activity ${ }^{7,8}$. Addition of dexamethasone increases the $\mathrm{pH}$ from 4.5 to 5.5 ,thereby increases the amount of free base of the local anaesthetic, decreases the time required for onset of the anaesthetic, decreases pain on injection, and also improves overall the patients postoperative comfort and quality of life as demonstrated by the postoperative VAS scores, measurements for the facial swelling, and the measurement of the reduction in mouth opening.

Laureano filho et $\mathrm{al}^{9}$ reported that in patients undergoing surgery for impacted third molars, treatment with dexamethasone always produced a good control of swelling, as measured 24 and $48 \mathrm{hrs}$. after surgery. In another study, submucosal administration of $4 \mathrm{mg}$ dexamethasone has been compared with that of $8 \mathrm{mg}$ dexamethasone plus $2 \mathrm{~g}$ augmentin 2 times a day. No difference was observed between the 2 dosage regimens.

Various other researchers like Messer and Keller $^{10}$, Elhag et $\mathrm{al}^{11}$ and Graziani et $\mathrm{al}^{12}$ have also established the beneficial usage of $4 \mathrm{mg}$ dexamethasone in patients of oral surgical procedures. Corticosteroid administration during the surgeries or in the post-operative period seems to give a great benefit for reducing the swelling and postoperative oedema. 
With use of corticosteroids, one major concern remains about the healing in the postoperative phase. Thorén $\mathrm{H}$ et $\mathrm{al}^{13}$ in their study on effects of perioperative glucocorticosteroids on disturbance in surgical wound healing have concluded that there remains no increased risk of a disturbance in bone healing with doses of $30 \mathrm{mg}$ or less of dexamethasone or equivalent.

Clinical recovery in all the patients in the group that received dexamethasone was uneventful. Several investigators have stated that corticosteroids are effective adjuncts in peri-operative pain management, although steroids do not have a clinically significant analgesic impact themselves. However, they do have some potential side effects such as adrenal suppression, hyperglycaemia, infections and delayed wound healing ${ }^{3}$.

\section{Conclusion:-}

The addition of dexamethasone to lignocaine significantly shortens the latency and prolongs the duration of the soft tissue anesthesia, with improved quality of life in the postoperative period after surgical extraction of mandibular third molars.

\section{Reference:-}

1. Bhargava D, Sreekumar K, Rastogi S,Deshpande A, Chakravorty N. A prospective randomized double blind study to assess the latency and efficacy of twin mix and 2\% lignocaine with 1:200000 epinephrine in surgical removal of impacted mandibular third molars: a pilot study: oral max surg (2013) 17:275-280.

2. Sortino F, Cicciu M. Strategies used to inhibit post-operartive swelling following removal of impacted lower third molar. dent res jour: oct 2011, vol 8, issue 4, 162-169.

3. Acham S, KlampflA,Ttruschnegg A, et al. Beneficial Effect of methylprednisolone after mandibular third molar surgery: a randomized, doble blind, placebo-controlled split mouth trial: clin oral invest(2013) 17:1693-1700.

4. Berrada R, Chassard D, Bryssine S, Berthier S, Bryssine B, Boulétreau P (1994) In vitro effects of the alkalinization of $0.25 \%$ bupivacaine and $2 \%$ lidocaine. Anne FrAnesthReanim 13(2):165-168.

5. Malamend SF. Buffering local anesthetics in dentistry. Pulse 2011;4(1):8-9

6. Cepeda MS, Tzortzopoulou A, Thackrey M, Hudcova J, Arora Gandhi P, Schumann R. Adjusting the pH of lidocaine for reducing pain on injection. Cochrane Database Syst Rev 2010; 12.

7. Cummings KC, Napierkowski DE, Parra-Sanchez I, Kurz A, Dalton JE, Brems JJ, Sessler DI. Effect of dexamethasone on the duration of interscalene nerve blocks with ropivacaine or bupivacaine. Br $\mathrm{J}$ Anaesth2011;107(3):446-453.

8. Tandoc MN, Fan L, Kolesnikov S, Kruglov A, Nader ND. Adjuvant dexamethasone with bupivacaine prolongs the duration of interscalene block: a prospective randomized trial. J Anesth 2011; 25 (5):704-709.

9. LaureanoFilho JR, Maurette PE, Allais M, Cotinho M, Fernandes C. Clinical comparative study of the effectiveness of two dosages of Dexamethasone to control postoperative swelling, trismus and pain after the surgical extraction of mandibular impacted third molars. Med Oral Patol Oral Cir Bucal 2008;13:129-32.

10. Messer EJ, Keller JJ. The use of intraoral dexamethasone after extraction of mandibular third molars. Oral Surg Oral Med Oral Pathol 1975;40:594-8.

11. Elhag M, Coghlan K, Christmas P, Harvey W, Harris M. The anti-inflammatory effects of dexamethasone and therapeutic ultrasound in oral surgery. Br J Oral MaxillofacSurg 1985; 23:17-23.

12. Graziani F, D’Aiuto F, Arduino PG, Tonelli M, Gabriele M. Perioperative dexamethasone reduces post-surgical sequelae of wisdom tooth removal. A splitmouth randomized double-masked clinical trial. Int J Oral MaxillofacSurg 2006;35:241-6.

13. Thorén H, Snäll J, Kormi E, Numminen L, Fäh R, IizukaT,Lindqvist C, Törnwall J. Does perioperative glucocorticosteroid treatment correlate with disturbance in surgical wound healing after treatment of facial fractures? A retrospective study. J Oral MaxillofacSurg2009;67(9):1884-1888. 